\title{
CLASSROOM PEDAGOGY IN GERMAN AND MALAYSIAN SECONDARY SCHOOLS: A COMPARATIVE STUDY
}

\author{
Salmiza Saleh ${ }^{1 *}$ and Liew Sang Sang ${ }^{2}$ \\ ${ }^{1}$ School of Educational Studies, Universiti Sains Malaysia, \\ 11800 USM Pulau Pinang, Malaysia \\ ${ }^{2}$ Sekolah Menengah Kebangsaan Datuk Patinggi Haji Abdul Gapor, 93350 Kuching, \\ Sarawak, Malaysia \\ ${ }^{*}$ Corresponding author: salmiza@usm.my
}

Published date: 31 March 2019

To cite this article: Salmiza Saleh, \& Liew, S. S. (2018). Classroom pedagogy in German and Malaysian secondary school: A comparative study. Asia Pacific Journal of Educators and Education, 33, 57-73. https://doi.org/10.21315/apjee2018.33.5

To link to this article: https://doi.org/10.21315/apjee2018.33.5

\begin{abstract}
The purpose of this study was to compare and investigate the similarities and differences of classroom pedagogy between German and Malaysian secondary schools. Two classes with almost similar characteristics conducted by experienced teachers (in Germany and Malaysia) were consecutively observed naturally for three periods of 90 minutes each within one month. The observations were orientated into frame and act based on A Generic Model of Teaching proposed by Robin J. Alexander. The field notes written during observations of the two classes were then transcribed, coded down and analysed qualitatively. Data obtained revealed that there were similarities as well as differences between classroom pedagogy with the two classes. The findings reported in this paper shall provide some insights on the educational setting in the secondary schools of both countries. The results can be used as a guide for us to improve the current classroom pedagogical practices.
\end{abstract}

Keywords: comparative, German, Malaysian, secondary schools, pedagogy

\section{INTRODUCTION}

Pedagogy is the method and practice of teaching, specifically in the context of a classroom, which involves the interactions between the teacher and the students. The teacher needs to plan his or her lesson and design the curriculum before entering the class so as to postulate worthy learning experiences for the students. 
Pedagogy can also be culturally dependent, as different nations and cultures have different understandings on what is effective teaching (Alexander, 2009). Certain cultures believe in nurturing a child's behaviour, some focus on the acquisition of knowledge and skills, while others may determine achievement or academic performances based on test scores.

Alexander (2009) described pedagogy as "the discourse with which one needs to engage in order both to teach intelligently and make sense of teaching" and pointed out that comparative pedagogy "identifies, explores and explains the similarities and differences in pedagogy". In his discussion on comparative pedagogy, Alexander (2009) proposed that there should be a defensible rationale and methodology for comparison, empirical procedures for studying and explaining the values and ideas in teaching, and how these methods and procedures are related at different levels in the context of an education system.

The framework for comparative pedagogy proposed by Alexander (2009) is an analytical model which consists of three parts. The first part considers the observable act of teaching, as Alexander (2009) defines pedagogy as the "observable act of teaching together with its attendant discourse of educational theories, values, evidence and justifications". The second part of the framework talks about the ideas, values and beliefs, which explain the act of teaching via three domains: classroom levels, system level and cultural level. The third part deals with the macro-micro relationship that links classroom transactions to national policy through the curriculum used.

According to Alexander (2001), "the fundamental concept of the framework is that the core acts of teaching (task, activity, interaction and judgment) are framed by space (classroom organisation), students' organisation, time and curriculum, and by classroom routines, rules and rituals. They are given in the form of lesson or teaching session". For the acts of teaching, tasks refer to what students are asked to do during a teaching and learning session, activities refer to what the students do in order to complete the tasks, interactions refer to the how the teacher organises and communicates the tasks and activities to the students, and judgements informs the criteria for the tasks and activities in order to differentiate a student's ability. Whereas for the frame, space refers to the organisation of classroom and the resources available to it, and differs based on the level of funding a school has. Student organisation shows how students are managed during lessons, whether individually, in groups, or as a class in whole. Time and curriculum refers to how effective time is managed and where the curriculum is concerned, including the pace of teaching and learning. Routine, rule and ritual form a micro-culture on a classroom, especially if the population of the students are diverse. 
These are the building blocks of teaching which form a lesson's frame in a classroom. Figure 1 shows the complete teaching framework proposed by Alexander (2001).

\begin{tabular}{|lll|}
\hline Frame & Form & Act \\
Space & & \\
Student organisation & & Task \\
Time & Lesson & Activity \\
Curriculum & & Interaction \\
Routine, rule and ritual & & Judgment \\
\hline
\end{tabular}

Figure 1. A generic model of teaching

According to Alexander $(2001,2009)$, lessons and teaching acts can be governed by space in which the way a classroom is organised, resourced and disposed. As recent study shows that the classroom environment can affect students' learning and academic progress by as much as $25 \%$ (Barrett, Davies, Zhang \& Barrett, 2015), and thus, it is vital to make sure that the classroom space is used wisely and the students be organised appropriately according to the objectives of the lesson. A suitable and creative learning environment, routine, rule and ritual as well as effective curriculum and time management could help engage students, encourage interaction among them, and bring out the best of their abilities (Hannah, 2013; Marzano, 2003; Sahitol, Khawaja, Panhwar, Siddiqui, \& Saeed, 2016; Stabback, 2016). Teachers are responsible for the spaces for teaching and learning and should attempt to make them exciting and stimulating.

Comparing different types of pedagogy employed by teachers in different classrooms enables the provision of insights as to what is the best practice in teaching, for students to gain meaningful learning experiences. Malaysia is a young country, which is developing towards a technology-based industrial nation. The country's educational policy is constantly evolving as part of the process of its national transformation. The Malaysian Ministry of Education is probing into the experience, as well as practices of developed countries, as an effort to refine the Malaysian education system, in the hope of obtaining a pedagogy that is most beneficial to its people. Thus, comparing the practices within a German classroom, as a model of a developed country, with that of a Malaysian classroom, may provide a clue as to how pedagogical practices can be refined and further improved.

Hence, the purpose of this study was to compare the classroom pedagogy between German and Malaysian secondary schools. Specifically, this research attempted to investigate the similarities and differences of classroom pedagogy between German and Malaysian secondary schools, based on the framework of A Generic 
Model of Teaching suggested by Alexander $(2001,2009)$. (In this study, the aspect of cultural background was not considered as part of our focus).

\section{METHODOLOGY}

A comparative case study design was employed to compare the classroom pedagogy in German and Malaysian secondary schools. A class of Grade Eight students in Leipzig, Saxony, Germany, and a class of Form Two students in Kuching, Sarawak, Malaysia were selected using the purposive sampling technique, to ensure that both had fulfilled certain similar characteristics. The German classroom (consisted of 24 students -10 boys and 14 girls) was based in a Gymnasium (high performance school) in Leipzig. The Malaysian classroom (consisted of 28 students-11 boys and 17 girls) was based in a government secondary school in Kuching. The school is recognised as an elite school from its academic achievement and awards received from the Ministry of Education. Both classes (in Malaysia and Germany) were made up of students aged around 14 years, from different ethnic backgrounds.

Data were collected via classroom observations of a lesson taught in English. The English subject was selected in order to reduce the possibility of differences in the subject matter and the type of language employed that might influence the validity of the data. The English lessons in the Grade Eight class (in Leipzig) were taught by Teacher $\mathrm{X}$ and the English lessons in the Form Two class (in Kuching) were taught by Teacher Y. Teacher X and Teacher Y were female and had experienced of teaching English for more than 10 years.

Both classes were consecutively observed naturally for three periods of 90 minutes each during their English lesson, within one month. Throughout each lesson, any aspects that related to the the acts of teaching and the frame of the classroom were recorded in the form of field notes. All the six field notes were then transcribed, coded down based on the predefined categories suggested by A Generic Model of Teaching (Alexander, 2001, 2009) and analysed qualitatively using Braun and Clarke's framework (Braun \& Clarke, 2006) of thematic analysis approach.

\section{RESULTS AND DISCUSSION}

Findings were organised according to the framework for comparative pedagogy proposed by Alexander (2001, 2009), which focuses on the frame and acts of teaching. Situations between the German classroom pedagogy and the Malaysian classroom pedagogy were compared and discussed. 


\section{Frame: Space}

In the Gymnasium in Leipzig, Germany, each classroom is unique to the teacher. The class is the space where the teacher works and interacts with the students. Students from different grades come to the room when they have a lesson with the teacher. There is a time interval of 10 minutes for students to change their classrooms. The observations were done in the classroom of an English teacher, Teacher X. The furniture in the room were organised in such a way that it is more suitable for teaching. Students' desks were arranged in a manner that enables group discussion between students. Student desks and chairs in the classroom were made from lightweight materials, which allow them to be easily moved around, if necessary, to facilitate learning activities. In addition, there were posters and maps on the walls, mostly related to the United States of America. A conversation with the teacher revealed that she was teaching a topic which is related to the country, therefore she used the maps and posters for discussions from time to time. The classroom layout was still conventional, with the use of chalk and blackboard as writing board. However, the researcher was told that the chalk used was a special chalk that does not have any side effects. The room was airy with large window panes to provide enough natural lighting into the room. The cabinets were placed at the back of the room to keep dictionaries and other reading materials that students may need for reference during the lessons.

The layout of the classroom in the elite government secondary school in Kuching, Sarawak, Malaysia was similar to that of the Gymnasium in Leipzig, Germany, with the arrangement of desks and chairs also suitable for teaching. Students' desks were also arranged to enable group discussion between students. However, the desks and chairs were quite heavy, compared to the ones used in Germany. The classroom was occupied by the students. Teachers enter the classroom when they have lessons with the students. Notice boards at the back of the room exhibited students' works on different subjects that they were learning, such as science, mathematics, history, geography and language studies. The classroom under observation had a mini library, where books were kept on shelves at the back of the room. Apart from the writing board (whiteboard), there were no other resources for the teacher in the classroom. Teachers will have to bring along reading materials into the classroom, if they were to be used during lessons. These materials were usually kept at the teachers' office.

\section{Frame: Student Organisation}

In the case of the Teacher X (Grade Eight classroom in Germany), the organisation of students depended on the content that she wanted to deliver. Teacher X treated 
her students as a whole. Students were often required to sit in groups or in pairs to facilitate the discussion amongst themselves. Hence, Teacher $\mathrm{X}$ made sure that every student participated in the discussion. Furthermore, she would call upon individual students to read aloud their work while others gave comments. Therefore, collectivism was practiced by Teacher X.

In the Form Two classroom observed in the secondary school in Kuching, Sarawak, Malaysia, the organisation of students was already fixed. Most of the learning activities were limited around students' desks. Similar to Teacher X, Teacher $\mathrm{Y}$ also treated her class as a whole. Teacher $\mathrm{Y}$ also divided the students quite often into smaller groups to discuss the tasks given to them. This meant that the organisation has changed from collectivism to community.

\section{Frame: Time and Curriculum}

As both teachers were experienced teachers, they did not have a lot of problems with time management. The only difference between Teacher X and Teacher Y was the time allocated for social interaction with their students. Teacher Y utilised a lot more time to talk about things that were out of lesson context compared to Teacher X, who seemed to use most of her time to talk about things that were related to the lesson. Compared to Teacher Y, Teacher X conducted more tasks such as analysing, discussing, writing, speaking during the period of her lesson. Thus, in terms of lesson pace, it was found that the teaching and learning activities in Teacher X's classroom progressed much faster compared to the Teacher Y's classroom.

Curriculum, in this context, are the lessons and academic contents taught in each classroom. In this case, the curriculum or subject matter involved was English for students aged around 14. Both the English lessons conducted in the observed classes seemed to focus on three main skills, which were writing, speaking and grammar. Observations showed that there were no significant differences in terms of curriculum delivery in this research context.

\section{Frame: Routine, Rule and Ritual}

In the classroom of Teacher X in Leipzig, Germany, the majority of the students in the class were Germans, of different ethnic descents. There were only a few nonGerman students whose parents were in Germany on official or financial purposes, and thus were able to converse in more than one language. Students participated actively in the class discussion but did not make much noise. The students raised their hands when they wanted to answer a question or state their ideas. However, 
they would not speak out until and unless their names have been called out. There seemed to be a mutual understanding between the teacher and the students on when and how they can voice out their thoughts. Conversations between students were just whispers or gestures towards each other.

Whenever Teacher $\mathrm{X}$ posed a question to her class, students would volunteer to answer. There were at least six hands that were raised every time a question was asked. There were certain students who were more proactive than others, and girls were observed to be more active than boys. Teacher X expected her students to be attentive to her class discussion, and would make sure that all students were paying attention before allowing anyone to speak up. By doing this, Teacher X was able to keep her classroom in control. She made it obvious to the students that she was still 'the one in-charge' in the classroom.

Compared to Teacher X's class, Teacher Y's class in Kuching, Sarawak was a little passive, whereby students did not talk much and were just waiting for her to give directions for most of the activities. The students in the class were multiracial, from different ethnic groups in the local society, which included the natives and non-natives. Although they have different mother tongues, communication was not a problem as they have all studied and learnt the national language, the Malay language, and also the English language, since elementary school. In spite of this, whenever the teacher posed a question, there was usually no active response from students, until the teacher called their names out individually. It seems that Malaysian students do not have the habit of raising hands to answer questions. If they were requested to give out ideas or comments, they just stated their views aloud, more or less simultaneously, which made the classroom very noisy at certain times. When this happened, Teacher $\mathrm{Y}$ had to verbally order the classroom back to silence.

\section{Act: Task and Activities}

The first task that Teacher X prepared for her students was to write a story on a shocking event. She prepared a hand-out depicting cartoon characters of two hikers experiencing a shocking event. Features of the shocking event were discussed and students prepared a story based on either the cartoon characters in the hand-out or out of their own creativity. The students were to share the stories that they had written with their classmates. Teacher $\mathrm{X}$ allowed the students to volunteer before choosing who is to read aloud their work. Two students were then chosen to present their work. Then, the other students were asked to evaluate their friends' work. The students were proactive and volunteered to give feedback to their friends' work. Those who did not write their story were then called upon to do the 
evaluation. Thus, the activities during that lesson included reading, assessing and evaluating. Teacher $\mathrm{X}$ also encouraged peer assessment before giving her feedback to the students.

Teacher Y, on the other hand, prepared a title, "An Unforgettable Event in My Life" for her students to write an essay on and there were no hand-outs. She asked probing questions to brainstorm students' ideas on their unforgettable events. Then, she explained how a descriptive essay should be written using the ideas given by the students. She also introduced new vocabulary that could be used in the writing. The activities in Teacher Y's classroom did not seem to involve the students much. Teacher Y subsequently divided the class into small groups of four to five students each so that they were able to have group discussions on how the essay can be written, as well as on how to complete the grammar exercises. Students were to choose one specific event among themselves and present the outline of the essay before proceeding to the actual writing. Thus, the activities changed from lecturing to group discussion.

The second task that Teacher $\mathrm{X}$ had prepared to her students was to practice speaking English with their peers. Students were given several situations and they had to act out each situations as if they were tourists (to ask questions) and locals (to give directions). Each student was first asked to read aloud the given instruction to their partners, communicate with their partners about the situations and then summarised what they had communicated. Each student was actively involved in all the learning tasks. For the activity related to oral skills, in Teacher Y's classroom, students were asked to read aloud passages in their textbooks in a group and also individually. The teacher then asked her students questions related to the passages that they have read. Students were required to discuss amongst themselves the answers and then appoint a representative to read aloud the answers in front of the classroom.

The third task that Teacher X prepared for her students was on learning grammar. Teacher $\mathrm{X}$ asked her students to analyse several pictures given to them and create sentences using the correct grammar. Students were asked to come out in front of the classroom and read aloud the sentences that they have created. At the same time, the rest of the class were also allowed to ask questions regarding the pictures and give comments on the appropriateness of the sentences. Teacher $\mathrm{X}$ then discussed and confirmed the sentences. On the contrary, grammar learning in Teacher Y's class occurred by the way of lecturing and discussing important points first, followed by students conducting related exercises. Several examples were provided during the lecture and discussion phase. Teacher $\mathrm{Y}$ also requested the students to also provide some more related examples. She then asked the students 
to complete the grammar sheets given to them, and discussed the answers with them before the end of the class session.

\section{Act: Interactions and Judgement}

The interactions between teacher and students in the classroom occurred through a series of questions, feedbacks and code-switching. The teacher posed questions to explore students' ideas and in turn, the students asked the teacher questions to understand what the teacher's expectation of them is. Another kind of interaction was the feedback that teachers gave to the students when they answered a question, or completed certain tasks. In addition to that, code-switching was used to help students better understand the instructions, questions and answers which were quite complicated. Teacher X seemed to use a lot of hand gestures to encourage her students to speak. She did not move much around the room and was always standing in front of the class. Teacher Y, on the other hand, moved a lot in the classroom as she was asking her class to do group discussions. Hence, she moved from group to group providing guidance to the students.

\section{Questioning techniques}

In the class in Leipzig, Teacher X asked questions to check on the students' status. Before a student acted upon her command, she would ask:

Teacher X: Is everybody here with us? Everyone listening?

Students: (together) Yes.

This question was a 'commit' type of elicit questioning in the analysis framework of Kao, Carkin and Hsu (2011) as it required the students' action to commit to the discussion going on in the class. Teacher $\mathrm{X}$ also used inquiry questioning such as:

"Any questions about the story before evaluation?"

The purpose of this question was to check whether or not the students understand the story read out by their friend, hence the type of elicit questioning was an 'understanding check'.

When inviting students to evaluate their friend's work, Teacher X used spiral questioning to guide the students on how to give out comments:

"Did you enjoy the story?" 
"Are you clear about the story?"

"What are the vocabulary used in the story?"

Teacher X actually had an answer in mind that she expected the students to reply back. Thus, the type of elicit was 'agree' and 'clarify'.

The questioning technique used by Teacher $\mathrm{Y}$ in the class in Kuching was quite limited compared to Teacher $\mathrm{X}$, as she only asked surface questions to brainstorm the students' ideas. She used inquiry questioning and "add on" responses:

"What are the things that happened when you were young and you still remember vividly until now?"

"So what are the most unforgettable events in your life?"

"Can you add on to what had just said?"

Teacher Y used more questions which required information from the students which meant that the type of elicit is 'inform'.

Overall, Teacher X's questioning technique seems to be more structured and specific in helping students learn the lesson optimally compared to Teacher Y's approach. These differences were probably due to the different type of pedagogy practiced by the teachers and the tasks employed in their respective classrooms.

\section{Code-switching}

Teacher Y used code-switching during language lessons for reiterative purposes. Although the students were from different ethnic groups, they were fluent in the Malay Language, especially the native group. Hence, Teacher Y used the Malay Language and sometimes a more localised Sarawakian dialect to explain the vocabulary and clarify instructions, especially when she did not get any responses from the students. As Teacher Y allowed code-switching in the class, some of her students would mix the languages used in their questions or expressions. For example, when Teacher Y asked the students to describe a happy experience:

Teacher Y: Give me examples of good deeds that you have done in life.

Student 1: Helping the ... err... orang buta to cross the road.

Teacher Y: Orang buta?

Student 2: I know! Blind people! 
The first student was unsure how to state blind people in English and decided to use the Malay Language instead, but her classmates helped him translate it into English. However, as the class of Teacher Y was considered a class from an elite school, most of the students were fluent in English hence the use code-switching for reiterative purpose were not frequent. Only students who have no confidence in speaking English would respond to her using the Malay Language. For example:

Teacher Y: Now sit in a group of four and discuss how you will write your essay.

Student 3: Madam, group kami tiga orang sahaja (...our group has only three people).

In general, the main language used during the English lesson of Teacher Y was still English, especially when she addressed the whole class. Only when an individual student referred to her for advice or explanation, she would switch to other languages so that the student can understand better.

However, Teacher X did not approve of code-switching in class. Her class was conducted in English only and she discouraged students from using the German language in her class. When a student asked her something about the content of the lesson in German, Teacher X wanted the student to rephrase the question into English. On the other hand, there was a list of English-German vocabulary pinned on the wall to help students understand the English vocabulary. Towards the end of the lesson, a student asked for instruction in the German language and Teacher $\mathrm{X}$ gave the desired feedback as she commented that this was a good question that required the information everyone in the class needed. Hence, German language was still used to support the learning of the English language.

\section{Effective feedback}

Teacher X gave feedback to each statement made by the students using words such as good job, excellent, interesting, and so on. She also used phrases like "this is interesting", "you have a point there". She also asked the rest of the students to evaluate their classmates' work before giving her opinion, stating the strength and weaknesses of the writing presented by the students. Teacher X was observed to take down notes on her notebook when the students speak, so that she could return to a point mentioned earlier by the students. However, Teacher X used instructive words when her students' did not do what she expected.

"Do not retell the story! Evaluate!" 
Teacher X used a lot of hand gestures to encourage her students to speak. She did not move much around the room and was always standing in front of the class.

Teacher Y, on the other hand, moved a lot in the classroom as she was asking her class to do group discussion. Hence, she moved from group to group providing guidance to the students. During class discussion, she also used words of praise such as good, nice, wonderful, et cetera. However, sometimes she just smiled when students gave opinions. According to Teacher Y, she tried her best not to give negative feedback to the students during class discussion, unless there is a mistake that she must correct.

\section{Judgement}

Judgement involves teacher's assessment decision-making processes and his or her ability to be both "accurate" and "fair" to their students. In both the classrooms, both Teacher X and Teacher Y have shown their credibility as good teachers who were trying to assess their students accurately and fairly. Apart from assessing students' performance by herself, Teacher $\mathrm{X}$ also asked students to evaluate their friends through peer assessment activities. Teacher $\mathrm{Y}$, however, had the tendency to assess her students by herself.

\section{Similarities and Differences of Classroom Pedagogy between German and Malaysian Secondary Schools}

The similarities of classroom pedagogy between German and Malaysian secondary schools could be seen in terms of several aspects, namely space, general classroom interactions and judgments. It was found that the physical appearance of the German and Malaysian classrooms is quite similar. The layout of the desks and chairs and the students' seating plan were arranged either in the form of group plan or pair plan. In terms of general classroom interactions, observations showed that both the German and Malaysian teachers were using the classroom discussion approach in their lessons. Both teachers tried to encourage their students to participate in class discussions, which showed an effort to involve the students as much as possible in the teaching and learning process. Both teachers also practiced effective feedback in their classrooms. Apart from that, both teachers also seemed to judge the students fairly. In short, both tried to use a student-centred teaching method, but it seemed that the teacher still dominated the classroom.

The differences in classroom pedagogy between German and Malaysian secondary schools are obvious in terms of its classroom organisation, the organisation of 
students, time management, routine, rule and ritual, task and activities, interactions and judgement.

\section{Classroom organisation}

In Leipzig, Germany, students move from classroom to classroom. There is a time interval of 10 minutes for students to move around between lessons to change the classroom. Movements between classes gave students a chance to engage in physical activity, which can prevent them from becoming restless or bored from sitting in the same room all the time. This is a good practice as physical activity might improve students' health and self-efficacy and alleviate stress (Kall, Nilsson \& Linden, 2014). Whereas in Kuching, Malaysia (as well as the whole of Malaysia), it is the teacher who moves from classroom to classroom. Malaysian students are to stay in the classroom until break time. Since a student's desk is quite heavy, there are not a lot exciting learning activities which involve a lot of movements could be conducted within the classroom. This causes the students to become quite restless after a few lessons.

\section{The organisation of students}

In the classroom observed in Leipzig, Germany, students were often required to sit in a group or in pair to facilitate discussion among them. Students sometimes were asked to move aside their desks and sit on the floor in a group, if necessary. In the classroom observed in Kuching, Malaysia, the organisation of students can somehow be said as fixed. Most of the learning activities were limited around students' desks. However, with the increasing popularity of 21 st century skills and 21 st century classrooms, more and more schools are trying to improvise a different arrangement of desks and chairs in the classroom in order to accommodate the needs of group work, which is believed to enhance 21 st century skills. Hence, it can be inferred that layout of classroom is currently experiencing a change in Malaysia.

\section{Time management}

Observations showed compared to the German teacher, the Malaysian teacher is more lenient in her time management. Malaysian teacher is found to use much more time for social interactions with her students, which is also critical for students' academic progress (Hurst, Wallace, \& Nixon, 2013). However, the German teacher used most of the time allocated to talk about things that are related to the lesson only. The German teacher also conducted more learning tasks such as analysing, 
discussing, writing, speaking and evaluating within her lesson. As teacher's time management influence students' academic performance, it is important for teachers to manage the classroom time effectively (Sahitol et al., 2016).

\section{Routine, rule and ritual}

In the German classroom, students participated actively in the class discussion but did not make much noise. Students would raise their hands to answer a question or state their ideas. They would not speak out if their names were not called and seemed to understand when and how they can voice their thoughts. Since this is practiced consistently, it has become a routine that facilitates classroom management (Andrew, 2009). The Malaysian classroom, however, was much more passive. Students would not raise their hands to answer a question or state their ideas but preferred to say them aloud in group (hence the classroom becomes noisy). This showed that they actually did not have enough self-confidence and are unsure of what to expect. When students do not know what to expect, they will have a difficult time understanding what is expected of them (Andrew, 2009). Establishing set rituals, routines and procedures for every aspect of the classroom is the key to establishing a positive, safe learning environment for students (http://schd.ws/hosted_files/acpsdadminpdjuly252016/c3/Rituals\%20and\%20 Routines\%20Article.doc). Research shows that student achievement is improved when students are actively focused on educational goals and this is made possible by establishing appropriate rituals, routines and procedures at the beginning of the school year.

\section{Task and activities}

Compared to the Malaysian teacher, the German teacher seemed to prepare and conduct more learning tasks and activities for her students within the period of a lesson. The German teacher also seemed to be more creative, by implementing a lot more fun tasks and learning activities that lead to student engagement. Since creative learning tasks are crucial for student engagement and brain executive functions development (Eames, Benton, Sharp, \& Kendall, 2006), it is important for teachers to be creative in executing their classroom pedagogy.

\section{Interactions}

The German teacher did not move and interact much whereas the Malaysian teacher moved around the class to interact with her students and to make sure that her students were able to complete the learning task appropriately. This practice 
could create a good rapport between the teacher and the students and therefore would facilitate both student motivation for learning and their enjoyment of the course, and enhance student receptivity to what is being taught (Buskist \& Saville, 2001).

\section{Questioning techniques}

The German teacher was found to use more elicit questions related to confirming the ideas, whereas the Malaysian teacher used more elicit questions related to informing the ideas. These differences were probably due to the different type of pedagogy practiced by the teachers and the tasks employed in their respective classrooms. As such, research shows that questions that focus on student attention on important elements of a lesson result in better comprehension than those that focus on unusual or interesting elements (Marzano, Pickering, \& Pollock, 2001).

\section{Code-switching}

Code-switching is quite common in Malaysian classrooms (Kamisah \& Misyana, 2011). Consistent with the previous findings (Kamisah \& Misyana, 2011), it was found that the Malaysian teacher would use a formal directive language when addressing the whole class but sometimes switched to other languages which are more 'friendly' to the students, especially during small group or pair discussions. Teachers' and students' usage of code-switching can be a beneficial language strategy, but it should depends on the students' language level (Svendsen, 2014). In the German classroom, code-switching was not approved. Therefore, it can be inferred that the use of different languages is common in a Malaysian classroom, even if it is a language lesson, which contradicts with the condition in a German classroom. Code-switching can be accepted to be the micro-culture in a classroom in Malaysia, as it is in the Malaysian society. However, it was not an encouraged act in Germany.

\section{Effective feedback}

Although both teachers were using positive feedbacks in their classrooms, the Malaysian teacher tend to provide feedback of students' questions and work by herself only. On the other hand, besides giving feedback by herself, the German teacher also involved her students to give feedback to their friends through peer activities. Research in this area shows that vague or critical feedback has been shown to be unrelated to achievement whereas praise and credible is positively related to student achievement (Marzano et al., 2001). 


\section{CONCLUSION}

To conclude, the research findings showed that although both the German and Malaysian teachers were trying to practice student-centered teaching approach, they still dominated their classrooms. As compared to the Malaysian classroom pedagogy, the German classroom pedagogy is more conducive to their students. In line with that too, Germans students have more advantages than Malaysian students. The similarities and differences of classroom pedagogy between German and Malaysian secondary schools are also found to be far more affected by the content of the lesson rather than the cultural background of the two countries. Different content in subject matter entailed different pedagogy. Hence, classroom pedagogy is planned according to what the teachers desire to deliver in a particular lesson.

\section{ACKNOWLEDGEMENTS}

This work was supported by the Universiti Sains Malaysia RUI Grant (8016006).

\section{REFERENCES}

Alexander, R. J. (2001). Culture and pedagogy: International comparisons in primary education. Oxford: Blackwell.

Alexander, R. (2009). Towards a comparative pedagogy. In R. Cowen, \& A. M. Kazamis (Eds), International handbook of comparative education (pp. 923-942). New York: Springer-Verlag.

Andrew, T. (2009). Creating classroom rituals: Routines aid sense of comfort and ease activity transitions. In Ritual and Routines Article. Retrieved from http://schd. ws/hosted_files/acpsdadminpdjuly252016/c3/Rituals\%20and\%20Routines\%20 Article.doc

Barrett, P., Davies, F., Zhang, Y., \& Barrett, L. (2015). The impact of classroom design on pupils' learning: Final results of a holistic, multi-level analysis. Building and Environment, 89, 118-133.

Buskist, W., \& Saville, B. K. (2001). Creating positive emotional contexts for enhancing teaching and learning. Association for Psychological Science (APS) Observer, March, 12-13.

Braun, V., \& Clarke, V. (2006). Using thematic analysis in psychology. Qualitative Research in Psychology, 3, 77-101.

Eames, A., Benton, T., Sharp, C., \& Kendall, L. (2006). The impact of creative partnerships on the attainment of young people. Slough: National Foundation for Educational Research (NFER). 
Hannah, R. (2013). The effect of classroom environment on student learning. Honors Thesis, paper 2375, Lee Honors College, Western Michigan University. Retrieved from https://scholarworks.wmich.edu/cgi/viewcontent. cgi? article $=3380 \&$ context $=$ honors_theses

Hurst, B., Wallace, R., \& Nixon, S. B. (2013). The impact of social interaction on student learning. Reading Horizons, 52(4), 375-398.

Kall, L. B., Nilsson, M., \& Linden, T. (2014). The impact of a physical activity program on academic achievement in a Swedish elementary school setting. Journal of School Health, 84(8), 473-480.

Kamisah, A., \& Misyana, S. H. (2011). Code-switching and code-mixing of English and Bahasa Malaysia in content-based classroom: Frequency and attitudes. The Linguistics Journal, 5(1), 220-247.

Kao, S. M., Carkin, G., \& Hsu, L. F. (2011) Questioning techniques for promoting language learning with students of limited L2 oral proficiency in a drama-oriented language classroom. Research in Drama Education: The Journal of Applied Theatre and Performance, 16(4), 489-515. https://doi.org/10.1080/13569783.2011.616399

Marzano, R. J. (2003). Classroom management that works. Alexandria VA: ASCD. Cell Classroom Management. Marzano outline review. SW 5.27.2010, 3-9.

Marzano, R. J., Pickering, D. J., \& Pollock, J. E. (2001). Classroom instruction that works (vol. 5). Alexandria, VA: Association for Supervision and Curriculum Development.

Sahitol, Z., Khawaja, M., Panhwar, U. M., Siddiqui, A., \& Saeed, H. (2016). Teachers' time management and the performance of students: A comparison of government and private schools of Hyderabad, Sindh, Pakistan. World Journal of Education, $6(6), 42-50$.

Stabback, P. (2016). What makes a quality curriculum? Current and critical issues in curriculum and learning, No. 2 IBE/2016/WP/CD/02. Retrieved from https:// www.ibe.unesco.org.

Svendsen, E. (2014). The influences of code-switching in the second language classroom in connection to language development. Retrieved from https://muep.mau.se/ bitstream/handle/2043/18110/Svendsen\%2C\%20Emelie.pdf 